\title{
A productivity analysis of the Italian gas retail market
}

\author{
G. Capece ${ }^{1}$, L. Cricelli ${ }^{2}$, F. Di Pillo ${ }^{1} \&$ N. Levialdi ${ }^{1}$ \\ ${ }^{I}$ Dipartimento di Ingegneria dell'Impresa, \\ Università di Roma "Tor Vergata", Italy \\ ${ }^{2}$ Dipartimento di Meccanica, Strutture, \\ Ambiente e Territorio Università di Cassino, Italy
}

\begin{abstract}
Owing to the process of liberalization, the European energy markets have undergone a radical transformation over the last decade.

In this paper we analyse the Italian natural gas market, focusing in particular on retail with the objective of assessing the performance of the natural gas retail operators whilst also taking into account the strategies adopted after the liberalization process.

To that aim, company performance is analysed using the Edgeworth index which enables an assessment of levels of both profitability and productivity. Two types of comparisons are carried out based on the processed data. The first of which concerns the size of the company and second regards the degree of specialisation or diversification of the services offered.
\end{abstract}

Keywords: gas market liberalization, Italian gas retail operator strategies, productivity analysis, Edgeworth index.

\section{Introduction}

The liberalization process of the gas market in Europe began in the late 1990s with the first gas directive (Directive 98/30/EC) [1], which established common rules regarding the transmission, storage, supply and distribution of natural gas. This process ended in 2003 with the Gas Directive 2003/55/EC [2], which is the European gas legislation in force at present.

The European Gas directive requires obligatory unbundling of transport and trading: i.e. all gas operators belonging to the member states must separate their gas transportation and trading functions into separate companies. 
Another key aspect of the liberalization directive is based upon the concept of 'eligible customers' which is a category of customers who have the freedom to choose their supplier and the right to acquire gas at a competitive price [3].

The European Gas directive was transposed into Italian law by Legislative Decree n.164/2000, known as the Letta Decree [4], which laid down important guidelines concerning the definition of the eligible customers, competition, and conditions of reciprocity.

The retail market has been chosen as the subject of this research paper since it is the only sector to be opened to free competition. The strategic choices made following liberalization in this sector are of much interest and thus have also been analysed in this paper. In reaction to the market being opened, the retail operators have implemented a strategy of diversification to minimize costs or have initiated mergers in order to consolidate their own position by means of integration with other firms distributed geographically across the nation. Such mergers have produced many multi-utility companies which also compete in various other energy sectors, such as the supply of water and electricity.

The purpose of this paper is to assess performance of natural gas retail operators by focusing on their productivity, while also considering the strategies adopted after the liberalization process. The analysis of performance is carried out using the Edgeworth index which permits an assessment of the level of company profitability and productivity.

After examining the literature this index was considered to be the most suitable for a retail market performance analysis as it allows comparisons of companies to be made both on the basis of the input and output prices on the one hand, and the productivity on the other. The main aim of this type of comparison is to determine whether the profits are exclusively due to a high mark-up, or rather mainly to a high level of productivity.

Starting from a previous research [5], our analysis takes two types of comparison into account in which the first considers the company size and the second deals with the degree of specialisation or diversification of the services offered. On analysing the results, the discriminatory factors in determining the performance trend were identified as being the company size, or the core business, or a combination of both of these.

This research paper is organized as follows: Section 2 provides a review of the literature relating to utility performance; Section 3 shows the data set chosen for the index application; Section 4 describes the main results of our work; Section 5 presents a comparative analysis with respect to the size of the company and the business strategy employed; Section 6 concludes.

\section{The productivity analysis}

The aim of this paper is to assess the performance of natural gas retail operators, focusing on three key measures of strategic performance: profit, productivity, and price differential. The methodology used expresses the three performance measures in a single unified equation utilising the Edgeworth index [6].

Alongside the surge of liberalization and regulatory reform, there has been increasing interest in the accurate evaluation of public utility performance. 
Whether or not these reforms have produced the expected results may be investigated by utilising various methods of performance evaluation. Even though industry analysts have long recognized the importance of accurate performance evaluation as a cornerstone for the improvement of company performance, they have had to overcome some major difficulties regarding the evaluation of the gas industry. Although there are several distinctive performance measures which provide a range of information (such as profit, labour productivity, end-use price, etc.), these measures are not necessarily correlated. For example, higher profit may result from excessive market power rather than from higher productivity. In such cases, performance evaluation based exclusively on a single specific measure may distort the perception of the overall performance of a utility.

Extensive research has previously been conducted to analyse one specific aspect of physical performance in the natural gas market, for example efficiency or productivity. Examples of research of this nature are listed in the following: Aivazian et al. [7] and Sickles and Streitwieser [8] explore the US natural gas industry; Rushdi [9] discusses an Australian gas utility and Price and WeymanJones [10] study the United Kingdom's natural gas distribution sector. Unfortunately, as far as the natural gas market is concerned there has been very little research relating to the simultaneous effects of various aspects of performance, such as price and profit. Indeed, numerous studies regarding productivity have only focused on productivity performance, i.e. the ability to obtain more output with less input. Likewise, exclusively studying the price differential of a utility (comparing the output price with the input price) would only provide us with an indication of the utility's ability to maintain its profit margin and value-focused performance.

Several studies indicate that the three different measures of performance (profit, productivity and price differential) should be considered simultaneously in order to obtain an overall picture of the performance of a utility [11, 12].

In contrast to the procedures used in the above studies, the methodology utilised in this paper has two distinctive features. Firstly, using the Edgeworth index the performance difference can be calculated in terms of absolute values, which helps decision-makers understand and evaluate strategic advantages. Secondly, it allows a multilateral comparison to be made, which is particularly useful should a panel analysis be required.

In relation to the Italian market, a performance analysis of the gas distribution sector was performed by Erbetta and Fraquelli [13] who utilised the Törnqvist index on the moving average without taking all three key measures of performance into account.

Our paper follows the analysis of Kim et al. [6] who evaluated performance in the gas sector through the use of the Edgeworth index, although their work concentrated on the segment of transport. The research presented here focuses on the retail sector since this is the area which has been most affected by the process of liberalization in Italy.

In order to explain the Edgeworth index, firstly the performance of two utilities $(\mathrm{l}$ and $\mathrm{k})$ is considered (bilateral comparison). The utility $1(\mathrm{l}=1,2, \ldots, \mathrm{L})$ 
consumes a varying amount of $\mathrm{n}$ inputs $\left(\mathrm{x}_{\mathrm{n}}{ }^{1}, \mathrm{n}=1,2, \ldots, \mathrm{N}\right)$ to produce $\mathrm{m}$ different outputs $\left(\mathrm{y}_{\mathrm{m}}{ }^{1}, \mathrm{~m}=1,2, \ldots, \mathrm{M}\right)$. Analogously, the utility $\mathrm{k}(\mathrm{k}=1,2, \ldots, \mathrm{M})$ also consumes a varying amount of $\mathrm{n}$ inputs $\left(\mathrm{x}_{\mathrm{n}}{ }^{\mathrm{k}}, \mathrm{n}=1,2, \ldots, \mathrm{N}\right)$ to produce $\mathrm{m}$ different outputs $\left(\mathrm{y}_{\mathrm{m}}{ }^{\mathrm{k}}, \mathrm{m}=1,2, \ldots, \mathrm{M}\right)$. Input and output prices are denoted by $\mathrm{w}_{\mathrm{n}}{ }^{1}$ and $\mathrm{p}_{\mathrm{m}}{ }^{1}$, respectively for utility 1 , and by $\mathrm{w}_{\mathrm{n}}{ }^{\mathrm{k}}$ and $\mathrm{p}_{\mathrm{m}}{ }^{\mathrm{k}}$ respectively for utility $\mathrm{k}$. The Edgeworth index is used to calculate the difference between the output price and the input price of the two utilities in absolute values. This index employs the output quantities of the two companies as weightings for input and output price aggregation, as follows:

$$
\begin{aligned}
& P_{k}^{l}=\sum_{m=1}^{M} \frac{\left(y_{m}^{k}+y_{m}^{l}\right)}{2} p_{m}^{l}-\sum_{m=1}^{M} \frac{\left(y_{m}^{k}+y_{m}^{l}\right)}{2} p_{m}^{k} \\
& W_{k}^{l}=\sum_{n=l}^{N} \frac{\left(x_{n}^{k}+x_{n}^{l}\right)}{2} w_{n}^{l}-\sum_{n=l}^{N} \frac{\left(x_{n}^{k}+x_{n}^{l}\right)}{2} w_{n}^{k}
\end{aligned}
$$

Price differential $P W_{k}^{l}$, which represents the effect of price on profit, can be defined as the difference between the output and input price, as follows:

$$
P W_{k}^{l}=P_{k}^{l}-W_{k}^{l}
$$

This value shall be referred to from here on as 'price effect'.

The effect of production efficiency is calculated by subtracting the input from the output quantity difference as shown below.

$$
\pi_{k}^{l}=\left(\sum_{m=1}^{M} \frac{\left(p_{m}^{k}+p_{m}^{l}\right)}{2} y_{m}^{l}-\sum_{n=1}^{N} \frac{\left(w_{n}^{k}+w_{n}^{l}\right)}{2} x_{n}^{l}\right)-\left(\sum_{m=1}^{M} \frac{\left(p_{m}^{k}+p_{m}^{l}\right)}{2} y_{m}^{k}-\sum_{n=1}^{N} \frac{\left(w_{n}^{k}+w_{n}^{l}\right)}{2} x_{n}^{k}\right)
$$

This value shall be referred to from here on as 'productivity effect'.

The variation in profit depends on the price difference and on the productivity (eqns 3 and 4).

The bilateral system does not satisfy the transitivity condition which is particularly important when comparing more than two utilities or performing a panel consisting of cross-sectional data.

Caves et al. [14] suggest that the transitivity condition could be met by introducing a hypothetical utility $h$. This utility $h$ would have all its data equal to the sample means, and would then be used as a benchmark against which to measure all the other companies.

\section{Data set}

The data set, which was supplied by the Unione Italiana delle Camere di Commercio (Italian Union of the Chambers of Commerce), is comprised of 100 companies operating in Italy and includes their balance sheets.

The cross-sectional analysis which was performed refers to 2005. Since most of the retail companies are currently in the start-up phase, it was not possible to carry out an analysis which took series of historical data from the balance sheets into consideration. In fact most of the companies studied were formed between 2003 and 2005, which is too short a time period to obtain significant data.

On 31 December 2005, there were a total of about 400 companies authorised by the 'Ministero delle attività produttive' (Ministry of Productive Activities) to 
practise retail activities in the end market, but according to research undertaken by the Italian Regulatory Authority for Electricity and Gas (AEEG) only 257 of these companies appear to be active. Therefore our sample, which includes approximately $39 \%$ of the companies that are actually in business, is in fact a significant amount of the total number of retail companies.

The companies analysed have been divided according to their revenue into three groups: small, medium and large companies. 'Small' companies are considered to be those with an income of less than $€ 10$ million; 'medium' are those with an income of between $€ 10$ million and $€ 50$ million; and 'large' those which have an income which is greater than $€ 50$ million. Thus our sample is comprised of 38 small companies, 38 medium companies and 24 large companies.

It is assumed that the output of the natural gas retail sector is the quantity of gas sold, and that the main inputs are raw material (methane gas); labour; and indirect expenses/overheads, such as administrative costs which would include telephone calls, postage, publicity and sponsorship.

In order to apply Edgeworth's multilateral model, a hypothetical 'ideal company' $h$ must be identified for every group, which shall then be used as a benchmark against which to measure the other companies [14]. Table 1 below shows these reference values for the benchmark company $h$ in each group.

Table 1: $\quad$ Input and output values for company $h$.

\begin{tabular}{|l|c|c|c|c|c|}
\hline Company $\boldsymbol{h}$ & \multicolumn{2}{|c|}{ Output } & \multicolumn{3}{c|}{ Input } \\
\hline & $\begin{array}{c}\text { Gas sold } \\
\text { Million }^{3} \text { ) }\end{array}$ & $\begin{array}{c}\text { Profit } \\
\text { (Thousands } \\
\text { of euros) }\end{array}$ & $\begin{array}{c}\text { Total Costs } \\
\text { (Thousands } \\
\text { of euros) }\end{array}$ & $\begin{array}{c}\text { Gas } \\
\text { purchased } \\
\text { (Million } \mathrm{m}^{3} \text { ) }\end{array}$ & $\begin{array}{c}\text { Number of } \\
\text { Clients }\end{array}$ \\
\hline Small company & 12.45 & 4,118 & 4,236 & 12.54 & 1,798 \\
\hline $\begin{array}{l}\text { Medium } \\
\text { company }\end{array}$ & 72.5 & 24,166 & 24,409 & 73.7 & 29,650 \\
\hline Large company & 1,038 & $3,617,000$ & 839,000 & 1,636 & 676,248 \\
\hline
\end{tabular}

\section{Analysis of the results}

Through the use of the Edgeworth index it was possible to identify the way in which each company differed from the ideal company $(h)$ in terms of: input costs, output costs, price differential, productivity, and profit. After having compared all the results for the companies, a graph of dispersion was plotted for each group in which the productivity effect was compared with the price effect. The gap between each company and the ideal, and the area where companies have a positive profit change may be seen from the graphs below.

In figure 1 , the $\mathrm{x}$-axis represents the productivity effect and the y-axis denotes the price effect. As stated above, the profit change is given by the sum of the productivity effect and the price effect, and thus the area above the bisector indicates a positive profit change where the greatest profits are to be found in the first quadrant. Companies below the bisector have a negative profit change and in the third quadrant both their productivity differences and price differences are negative. 


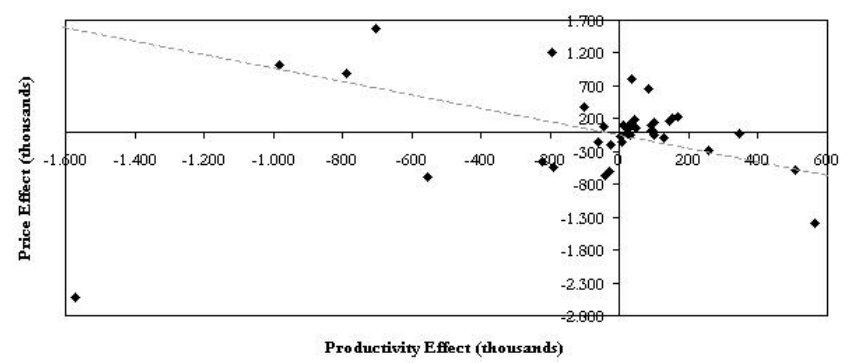

Figure 1: Performance trend of small companies.

As may be seen from figure 1, the small companies are very concentrated around the group average. There are small differences in profit and in price differential with respect to company $h$. This result may be due to the homogeneity of the organizational structure which typifies the small companies. Traditionally the small gas retail companies in Italy have always operated at a mainly local or provincial level, representing real local monopolies. Thus the only distinguishing factor between them is that of their geographic location.

In the analysis of the medium and large companies, there is a further subdivision to be considered regarding the strategy implemented following the liberalization of the sector. Many of the companies in these two groups have chosen a diversification strategy, operating not only in the field of gas retail, but also in those of the retail of other services, such as electricity and water.

The results suggest that as the dimensions of the businesses increase, the more companies tend to use diversification strategies. Indeed $67 \%$ of the large companies also compete in other sectors, a proportion which falls to $34 \%$ when referring to the medium companies. And only $5 \%$ of the small companies have diversified their businesses, which is the reason that they have not been considered in this analysis.

Figure 2 examines the performance trend of the medium companies. Firstly, it should be noted that with respect to the bisector there is less concentration around the average compared with the degree of concentration of the small companies. Moreover it can be seen that most of the medium companies are found above the bisector and thus have a positive profit change. In reality, such a result is due to the high level of productivity efficiency attained by medium companies, rather than being due to the mark-up achieved by these companies.

Most of the medium multi-business companies are positioned above the bisector, although many of these are found in the fourth quadrant where the mark-up obtained is below average.

In figure 3, the productivity effect and the price effect for large companies are compared. Firstly, it may be observed from the graph that there is a greater concentration of large companies in comparison to that of the medium companies. In relation to profitability, it should also be noted that approximately half of the companies manage to obtain a positive profit change and that this result is due to an increased mark-up rather than a greater level of productivity. 
The large multi-business companies are almost equally divided between the area above and below the bisector.

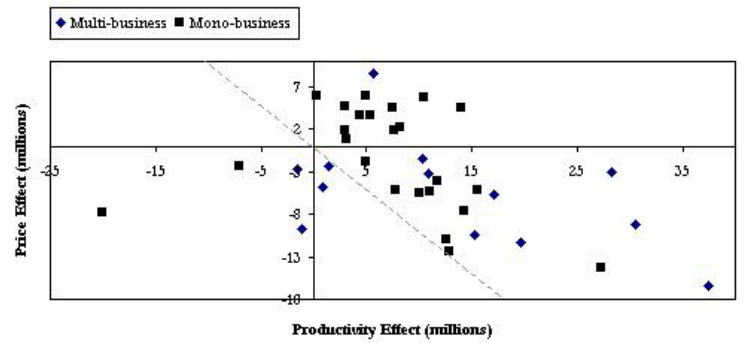

Figure 2: $\quad$ Performance trend of medium companies.

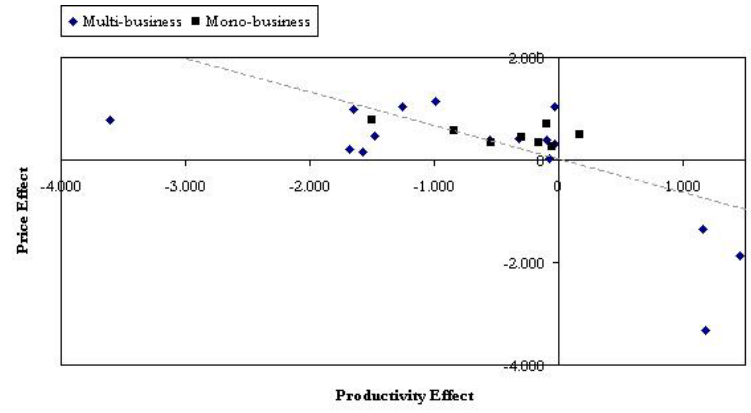

Figure 3: $\quad$ Performance trend of large companies.

\section{Comparative analysis}

It is interesting to analyse business performance in relation to company size and strategy adopted (diversification/specialisation).

The main performance results for each group, summarised in table 2, indicate that the most profit change is obtained by the medium sized companies, whilst the large companies show the least profit change. The high performance level of the medium companies is due to their greater productivity rather than to a larger mark-up. The opposite is true of the large companies which, thanks to their market power, manage to establish a higher mark-up. In fact $87 \%$ of the large companies boast a higher than average price differential owing to their greater bargaining power which allows them to purchase gas at lower prices from the suppliers. Despite such bargaining power, only $46 \%$ of the large companies have a positive profit change on account of the low level of productivity of the companies analysed. In fact only $17 \%$ of the large companies manage to attain a positive productivity change, a result which highlights an inefficient and wasteful allocation of resources.

In table 3, the multi-business companies and mono-product companies are compared in an attempt to determine whether the strategies adopted by the companies have a positive effect on profitability and productivity. 
Table 2: $\quad$ Comparison of results for small, medium and large companies.

\begin{tabular}{|l|c|c|c|}
\hline Group & $\Delta$ profits $>0$ & Price differential $>0$ & $\Delta$ productivity $>0$ \\
\hline SMALL & $63 \%$ & $42 \%$ & $63 \%$ \\
\hline MEDIUM & $84 \%$ & $53 \%$ & $89 \%$ \\
\hline LARGE & $46 \%$ & $87 \%$ & $17 \%$ \\
\hline
\end{tabular}

Table 3: Comparison of results for specialised/diversified companies.

\begin{tabular}{|c|l|c|c|c|}
\hline Group & Strategy adopted & $\boldsymbol{\Delta}$ profits $>\mathbf{0}$ & $\begin{array}{c}\text { Price } \\
\text { differential }>\mathbf{0}\end{array}$ & $\Delta$ productivity $>\mathbf{0}$ \\
\hline \multirow{2}{*}{ MEDIUM } & Specialised & $92 \%$ & $52 \%$ & $92 \%$ \\
\cline { 2 - 5 } & Diversified & $69 \%$ & $8 \%$ & $85 \%$ \\
\hline \multirow{2}{*}{ LARGE } & Specialised & $63 \%$ & $100 \%$ & $13 \%$ \\
\cline { 2 - 5 } & Diversified & $37 \%$ & $69 \%$ & $19 \%$ \\
\hline
\end{tabular}

In general the results from the medium and large companies indicate that those companies which have specialised attain a greater profit change than those which have diversified. This is mainly because on the whole specialised companies manage to obtain a greater mark-up than diversified companies. Such a disparity in mark-up is possibly due to the pricing strategies adopted by companies which decide to enter new markets. By reducing prices in the core business segment, the diversified companies offer clients an incentive to subscribe to their other utilities. The main aim of promotional initiatives of this nature is to subsidise the supply in the new markets.

With regard to productivity, the results show no significant difference between the specialised companies and the diversified companies in either group. Regardless of whether the companies are mono-business or multi-business, there is a low proportion of large companies which have attained a high level of productivity. Low levels of productivity in multi-businesses would appear to be counterintuitive since theoretically diversified companies ought to obtain a higher level of productivity thanks to the economies of scope. However in practice, given that the process of diversification has begun relatively recently, it is possible that more rewarding effects of this strategy have yet to mature.

\section{Conclusions}

This paper analyses the natural gas retail market following the relatively recent liberalisation of the sector.

In comparison to other sectors, the retail sector has been the most affected by liberalisation, and consequently many retail companies have used mergers in order to consolidate their market position. Further strategic options which were implemented after the market liberalisation were the specialisation of the core business or else diversification through entry into other markets such as those of electricity or water.

Following the liberalisation of the sector and the resulting tariff regulations it was interesting to analyse the market performance of the companies involved in gas retail, whilst considering the strategies used by these operators 
(specialisation/diversification). This analysis was carried out by applying the Edgeworth index, which enabled the integration of all three of the most important measures of strategic performance: profit, productivity and price differential.

Performance was studied by dividing the companies in the sample into three groups (small, medium and large). The data means of the companies in each group were used to define a hypothetical 'ideal company'. The companies in each group were then measured against our ideal company benchmark.

From our research it transpired that the medium sized companies have the best performance with respect to our ideal company in terms of profitability and productivity. In contrast the large companies mainly obtain positive profits due to an increased mark-up. On account of their greater bargaining power over suppliers, the large companies are able to purchase gas at lower prices.

In relation to the adopted strategies it is interesting to note that the specialised companies obtain a greater profit change with respect to diversified companies. Such a result may be due to the fact that the multi-utility companies are still in the start-up phase. Having to sustain greater reorganization costs, the diversified companies have not yet been able to take advantage of the economies of scope.

\section{References}

[1] European parliament and council Directive 98/30/EC of 22 June 1998 concerning common rules for the internal market in natural gas.

[2] European parliament and council Directive 2003/55/EC of 26 June 2003 concerning common rules for the internal market in natural gas and repealing Directive 98/30/EC.

[3] Capece, G., Di Pillo, F., Gastaldi, M., Levialdi, N., The European gas market: the effects of liberalization on retail prices, Energy and Sustainability, WIT Press, Volume 105, pp. 417-426, 2007.

[4] Ministry of Productive Activities Legislative Decree n. 164 of 23 May 2000, concerning the implementation of the Directive 98/30/EC and the common rules for the internal market in natural gas.

[5] Capece, G., Di Pillo, F., and Di Stefano S., La performance del mercato della vendita del gas naturale in seguito alla liberalizzazione del settore, Technical Report, Department of Industrial Engineering, University of Rome "Tor Vergata", 21st January 2008, pp. 1-35.

[6] Kim, T-Y., Lee, J-D., Park, S-B., Profit, productivity, and price differential: an international comparison of the natural gas transportation industry, Energy Policy, Volume 27, pp. 679-689, 1999.

[7] Aivazian, V.J., Callen, J.L., Chan, M.W.L., Mountain, D.C., Economics of scale versus technological change in the natural gas transmission industry, The Review of Economics and Statistics, Volume 69, Issue 3, pp. 556-561, 1987.

[8] Sickles, R.C., Streitwieser, M.L., An analysis of technology, productivity, and regulatory distortion in the interstate natural gas transmission industry: 
1977-1985, Journal of Applied Econometrics, Volume 13, Issue 4, pp. 377395, 1998.

[9] Rushdi, A., Productivity changes in the gas and fuel corporation of Victoria, Energy Economics, Volume 16, Issue 1, pp. 36-45, 1994.

[10] Price, C.W., Weyman-Jones, T., Malmquist indices of productivity change in the U.K. gas industry before and after privatization, Applied Economics, Volume 28, Issue 1, pp. 29-39, 1996.

[11] Miller, D., Profitability + Productivity = Price Recovery, Harvard Business Review, Volume 3, pp. 145-153, 1984.

[12] Banker, R.D., Chang, H.H., Majumdar, S.K., A framework for analyzing changes in strategic performance, Strategic Management Journal, Volume 17, Issue 9, pp. 693-712, 1996.

[13] Erbetta, F., Fraquelli, G., Produttività e redditività nella distribuzione locale di gas naturale in Italia: proprietà, diversificazione e scala operativa, L'Industria, Volume 4, pp. 745-768, 2003.

[14] Caves, D.W., Christensen, L.R., Diewert, W.E., Multilateral comparison of output, input and productivity using superlative index number, Economic Journal, Volume 92, pp. 73-86, 1982. 